\title{
Regional Differentiation of the Medial Prefrontal Cortex in Regulating Adaptive Responses to Acute Emotional Stress
}

\author{
Jason J. Radley, Carlos M. Arias, and Paul E. Sawchenko \\ Laboratory of Neuronal Structure and Function, The Salk Institute for Biological Studies, and Foundation for Medical Research, La Jolla, California 92037
}

\begin{abstract}
The medial prefrontal cortex (mPFC) is an important neural substrate for integrating cognitive-affective information and regulating the hypothalamo-pituitary-adrenal (HPA) axis response to emotional stress. $\mathrm{mPFC}$ modulation of stress responses is effected in part via the paraventricular hypothalamic nucleus (PVH), which houses both autonomic (sympathoadrenal) and neuroendocrine (HPA) effector mechanisms. Although the weight of evidence suggests that mPFC influences on stress-related PVH outputs are inhibitory, discordant findings have been reported, and such work has tended to treat this cortical region as a unitary structure. Here we compared the effects of lesions of the dorsal versus ventral aspects of mPFC, centered in the prelimbic and infralimbic fields, respectively, on acute restraint stress-induced activation of PVH cell groups mediating autonomic and neuroendocrine responses. Lesions to the dorsal mPFC enhanced restraint-induced Fos and corticotropin-releasing factor (CRF) mRNA expression in the neurosecretory region of PVH. Ablation of the ventral mPFC decreased stress-induced Fos protein and CRF mRNA expression in this compartment but increased Fos induction in PVH regions involved in central autonomic control. Repetition of the experiments in rats bearing retrograde tracer deposits to label PVHautonomic projections confirmed that ventral mPFC lesions selectively increased stress-induced Fos expression in identified preautonomic neurons. Finally, hormonal indices of HPA activation in response to acute stress were augmented after dorsal mPFC lesions and attenuated after ventral mPFC lesions. These results suggest that dorsal and ventral aspects of the mPFC differentially regulate neuroendocrine and autonomic PVH outputs in response to emotional stress.
\end{abstract}

Key words: ACTH; CRF; Fos; glucocorticoid; HPA axis; hypothalamus; paraventricular nucleus; prefrontal; stress

\section{Introduction}

The medial prefrontal cortex (mPFC) is involved in the processing of convergent cognitive and emotionally relevant information and in modulating attentional states (Bush et al., 1998, 2000; MacDonald et al., 2000; Kerns et al., 2004). Increasing evidence suggests that $\mathrm{mPFC}$ plays an important role in regulating the hypothalamo-pituitary-adrenal (HPA) response to emotional stress (Diorio et al., 1993; Figueiredo et al., 2003; Spencer et al., 2005). Such influences are mediated in large part via the paraventricular hypothalamic nucleus (PVH), which houses cell populations involved in the endocrine (HPA axis) and autonomic (sympathoadrenal) arms of the stress response. Corticotropinreleasing factor (CRF) released from neurosecretory cells in the parvicellular division of the PVH initiates the HPA stress cascade by stimulating the release of pituitary adrenocorticotropic hormone (ACTH), which, in turn, activates adrenal glucocorticoid

\footnotetext{
Received 0ct. 2, 2006; accepted Nov. 3, 2006.

This work was supported by National Institutes of Health Grant NS-49196 and was conducted in part by the Foundation for Medical Research. P.E.S. is an Investigator of the Foundation for Medical Research. J.J.R. was supported by the Anxiety Disorders Association of America and National Alliance for Research on Schizophrenia and Depression Young Investigator grants. We thank Kris Trulock for help in the preparation of the illustrations, Belle Wamsley for editorial assistance, Genelyn Vadney and Mark Dammann for technical assistance, and Yaira Haas for assistance with radioimmunoassays.

Correspondence should be addressed to Jason J. Radley or Paul E. Sawchenko, Laboratory of Neuronal Structure and Function, The Salk Institute for Biological Studies, 10010 North Torrey Pines Road, La Jolla, CA 92037. E-mail: radley@salk.edu or sawchenko@salk.edu.

DOI:10.1523/JNEUROSCI.4297-06.2006

Copyright $\odot 2006$ Society for Neuroscience $\quad 0270-6474 / 06 / 2612967-10 \$ 15.00 / 0$
}

secretion (Antoni, 1986). Separate and topographically organized populations in the parvicellular PVH project to CNS cell groups involved in autonomic control, including sympathetic preganglionic neurons (Saper et al., 1976; Swanson and Kuypers, 1980). Together, these effector systems serve to mobilize bodily resources to facilitate coping with acute emergencies, i.e., "fightor-flight" responses.

The weight of evidence from lesion studies suggests that mPFC influences on stress-induced HPA responses are inhibitory (Diorio et al., 1993; Brake et al., 2000; Figueiredo et al., 2003; Spencer et al., 2005). In these studies, lesions have tended to be focused on more dorsal aspects of the mPFC, predominantly the prelimbic (PL) and, to a lesser extent, anterior cingulate cortices (Diorio et al., 1993; Figueiredo et al., 2003). Dissenting reports describe altered basal, but not stress-induced, HPA secretory responses in rats bearing large $\mathrm{mPFC}$ lesions that also involve the more ventrally situated infralimbic area (IL) (Jinks and McGregor, 1997; Sullivan and Gratton, 1999, 2002). Based on these findings, the possibility of regional specialization has been raised (Herman et al., 2003, 2005; Sullivan, 2004) but not tested explicitly.

Although the $\mathrm{mPFC}$ has also been directly implicated in facets of autonomic regulation (for review, see Neafsey, 1990), relatively little attention has been paid to its involvement in the neural (sympathoadrenal) arm of the stress response. On the basis of connectivity (Hurley et al., 1991; Gabbott et al., 2005), this might be expected to be preferentially modulated by IL. Broader infer- 


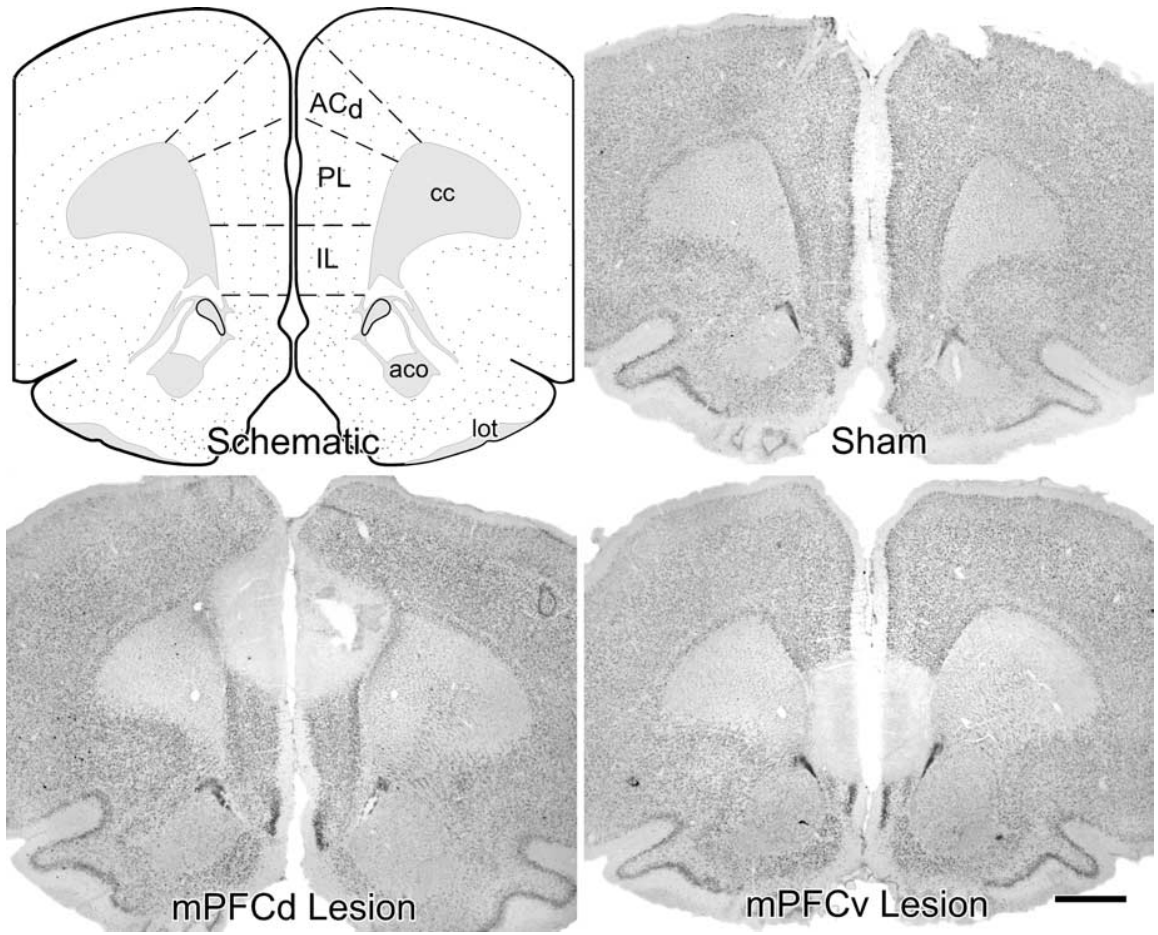

Figure 1. Dorsal versus ventral mPFC lesion placements. Atlas plate (modified after Swanson, 1992) and Nissl preparations of coronal sections through a similar level of the $\mathrm{MPFC}$ from representative sham-operated and dorsal and ventral mPFC-lesioned rats are shown. Damage from excitotoxin lesions was strongly centered in the PL and IL areas, respectively, with minor overlap. Dorsal lesions spread to involve aspects of the dorsal anterior cingulate region. cc, Corpus callosum, anterior forceps; aco, anterior commissure, olfactory limb; lot, lateral olfactory tract. Scale bar, $1 \mathrm{~mm}$ (applies to all).

ences drawn from work exploring modulation of stress-related affective behaviors (Morgan and LeDoux, 1995) raise the possibility that dorsal (PL) and ventral (IL) mPFC components may be differentiated with respect to both the nature of their influence over PVH effector mechanisms and the underlying circuitry (Heidbreder and Groenewegen, 2003).

In the present study, we compared the effects of dorsal (mPFCd) versus ventral (mPFCv) mPFC lesions on hormonal (ACTH and corticosterone) and histochemical (Fos induction, CRF mRNA) indices of HPA responses to acute restraint stress. Ancillary analyses were also performed to assess the impact of mPFC lesions on stress-induced activational responses of identified PVH preautonomic neurons.

Parts of this work have been published previously in abstract form (Radley and Sawchenko, 2005).

\section{Materials and Methods}

Animals and treatments. Adult male Sprague Dawley albino rats (275-325 g) were used in all experiments. They were housed individually in a temperature-controlled room on a $12 \mathrm{~h}$ light/dark cycle with the light period beginning at 6:00 A.M. Food (rodent chow 8604; Harland Teklad, Madison, WI) and water were available ad libitum. Rats were adapted to handling for at least $3 \mathrm{~d}$ before any manipulation. All experimental protocols were approved by the Institutional Animal Care and Use Committee of The Salk Institute.

The basic protocol involved subjecting separate groups of rats to bilateral injections of excitotoxin (ibotenic acid) into mPFCd, mPFCv, or a sham injection procedure. After a $14 \mathrm{~d}$ recovery period, rats were restrained at 9:00 A.M. in plastic restrainers (Braintree Scientific, Braintree, MA) for $30 \mathrm{~min}$. Controls were handled comparably but were not restrained. Stress exposure was timed so that all perfusions were performed during a $2 \mathrm{~h}$ window centered about the middle of lights-on phase of the diurnal cycle. All animals remained in their home cages during and after restraint until the prescribed time of perfusion for histology $(2 \mathrm{~h}$ after the termination of restraint) or during collection of repeated blood samples.

Excitotoxin lesions. Axon-sparing excitotoxin lesions were produced bilaterally by local microinjection of ibotenic acid $(10 \mathrm{mg} / \mathrm{ml}$; Sigma St. Louis, MO) in sterile saline. Injections were placed via pressure ejection (World Precision Instruments, Sarasota, FL) through micropipettes (10-20 $\mu \mathrm{m}$ inner diameter) to deliver $60-90 \mathrm{nl} /$ side at the following stereotaxic coordinates, with the skull flat between bregma and lambda: anteroposterior, $+2.90 \mathrm{~mm}$; mediolateral, $\pm 0.75 \mathrm{~mm}$; dorsoventral, $-2.50 \mathrm{~mm}$ from dura (mPFCd), $-4.33 \mathrm{~mm}$ (mPFCv). In shamlesioned animals, a burr hole was drilled in the skull and dura was removed in the location dorsal to $\mathrm{mPFC}$ lesion placements. The extent of damage to mPFCd and mPFCv was estimated by reconstruction from Nissl preparations (see Figs. 1, 2).

Labeling of central autonomic structures. The extent to which acute emotional stress-induced Fos-immunoreactivity (IR) within neurosecretory versus autonomic-related neurons in the PVH after mPFCd or mPFCv lesions was examined using retrograde transport methods. In one experiment, animals received crystalline deposits of fast blue (Sigma) into the rostral ventrolateral medulla to exploit the capacity of the tracer to be taken up and transported by axons-of-passage and thus provide for maximal labeling of $\mathrm{PVH}$ preautonomic cell groups projecting to both the dorsal vagal complex and preganglionic neurons in the spinal cord (Swanson and Kuypers, 1980; Sawchenko and Swanson, 1982). In another experiment, animals received injections of fast blue $(5 \% \mathrm{w} / \mathrm{v}$ in water; $500 \mathrm{nl})$ in upper thoracic (T1-T2) levels of the spinal cord (Sawchenko and Swanson, 1982). Tracer injections were made during the same surgical procedure when $\mathrm{mPFC}$ lesions were performed, and animals were allowed to recover for $14 \mathrm{~d}$ before the induction of stress. Dual immunoperoxidase labeling for Fos- and tracer-IR was performed by sequentially localizing the antiserum against Fos using a nickel-enhanced diaminobenzidine method (black nuclear reaction product), as above, and then a Fluorogold antiserum (Chang et al., 1990), which cross reacts with fast blue, without nickel enhancement (brown cytoplasmic product).

Histology and tissue processing. Rats were anesthetized with chloral hydrate $(350 \mathrm{mg} / \mathrm{kg}$, i.p.) and perfused via the ascending aorta at a flow rate of $55 \mathrm{ml} / \mathrm{min}$ with $100 \mathrm{ml}$ of $0.9 \%$ saline, followed by $900 \mathrm{ml}$ of ice-cold $4 \%$ paraformaldehyde in $0.1 \mathrm{~m}$ borate buffer, $\mathrm{pH} 9.5$. The brains were removed, postfixed for $3 \mathrm{~h}$, and cryoprotected in $20 \%$ sucrose in 0.1 $\mathrm{M}$ phosphate buffer overnight at $4^{\circ} \mathrm{C}$. Five one-in-five series of $30-\mu \mathrm{m}-$ thick frozen coronal sections through the entire brain were cut and collected in cryoprotectant solution and stored at $-20^{\circ} \mathrm{C}$ until processing.

Immunohistochemistry. Fos protein was detected using a rabbit polyclonal antiserum raised against the synthetic peptide SGFNADYEASSSRC, corresponding to residues 4-17 of human Fos protein (Ab-5, lot 4191-1-1; Oncogene Sciences, Uniondale, NY), used at a 1:10,000 dilution. Analysis of Fos-IR was performed on free-floating sections using a conventional avidin-biotin immunoperoxidase technique (Sawchenko et al., 1990). Endogenous peroxidase was neutralized by treating tissue for $10 \mathrm{~min}$ with $0.3 \%$ hydrogen peroxide, followed by $8 \mathrm{~min}$ exposure to $0.5 \%$ sodium borohydride to reduce free aldehydes. Sections were incubated with the primary antiserum at a dilution of $1: 10,000$ at $4^{\circ} \mathrm{C}$ for $48 \mathrm{~h}$ in PBS containing $0.3 \%$ Triton X-100 and 3\% blocking serum. The primary antiserum was localized using Vectastain Elite (Vector Laboratories, Burlingame, CA) reagents, and the reaction product was developed using a nickel-enhanced glucose oxidase method (Shu et al., 1988). Spec- 
ificity of the antiserum was evaluated by direct colabeling for $c$-fos mRNA over a range of challenge conditions (data not shown). In addition, specific staining in experimental and control tissue was abolished by preadsorbing the antiserum overnight at $4^{\circ} \mathrm{C}$ with $50 \mu \mathrm{M}$ of the synthetic peptide immunogen.

Hybridization histochemistry. Techniques for probe synthesis, hybridization, and autoradiographic localization of mRNA signal were adapted from Simmons et al. (1989). In situ hybridization was performed using ${ }^{35} \mathrm{~S}$-labeled sense (control) and antisense cRNA probes labeled to similar specific activities using a fulllength $(1.2 \mathrm{~kb})$ probe for mRNA encoding the hypophysiotropic neuropeptide CRF $(1.2 \mathrm{~kb}$; Dr. K. Mayo, Northwestern University, Evanston, IL). Sections were mounted onto poly-Llysine-coated slides and dried under vacuum overnight. They were postfixed with $10 \%$ paraformaldehyde for $30 \mathrm{~min}$ at room temperature, digested with $10 \mu \mathrm{g} / \mathrm{ml}$ proteinase $\mathrm{K}$ for $15 \mathrm{~min}$ at $37^{\circ} \mathrm{C}$, and acetylated for $10 \mathrm{~min}$. Probes were labeled to specific activities of $1-3 \times 10^{9}$ $\mathrm{dpm} / \mu \mathrm{g}$ and applied to the slides at concentrations of $\sim 10^{7} \mathrm{cpm} / \mathrm{ml}$, overnight at $56^{\circ} \mathrm{C}$ in a solution containing $50 \%$ formamide, $0.3 \mathrm{M}$ $\mathrm{NaCl}, 10$ mm Tris, 1 mm EDTA, 0.05\% tRNA, 10 $\mathrm{mm}$ dithiothreitol, $1 \times$ Denhardt's solution, and $10 \%$ dextran sulfate, after which they were treated with $20 \mu \mathrm{g} / \mathrm{ml}$ ribonuclease A for 30 $\min$ at $37^{\circ} \mathrm{C}$ and washed in $15 \mathrm{~mm} \mathrm{NaCl} / 1.5 \mathrm{~mm}$ sodium citrate with $50 \%$ formamide at $70^{\circ} \mathrm{C}$. Slides were then dehydrated and exposed to $\mathrm{x}$-ray films (Kodak Biomax MR; Eastman Kodak, Rochester, NY) for $18 \mathrm{~h}$. They were coated with Kodak NTB-2 liquid emulsion and exposed at $4^{\circ} \mathrm{C}$ for $3-4$ weeks, as determined by the strength of signal on film. Slides were developed with Kodak D-19 and fixed with Kodak rapid fixer.

Hormone assays. Separate groups of animals were implanted with indwelling jugular catheters $12 \mathrm{~d}$ after receiving $\mathrm{mPFCd}$, mPFCv, or sham lesions and $2 \mathrm{~d}$ before stress exposure. The procedures for implanting catheters have been described previously (Ericsson et al., 1994; Schiltz and Sawchenko, 2002). Briefly, indwelling jugular catheters (polyethylene PE 50) containing sterile heparin-saline $(50 \mathrm{U} / \mathrm{ml})$ were implanted under ketamine-xylazine-acepromazine anesthesia (25:5:1 mg/kg, s.c.). The sealed catheter was positioned with its internal SILASTIC (Dow Corning, Midland, MI) tip at the atrium and was exteriorized at an interscapular position. Blood samples (300 $\mu \mathrm{l})$ were taken before restraint stress to estimate basal ACTH and corticosterone levels. Additional samples were collected at 0,30, 60, and 90 min after the termination of restraint. Samples were collected into chilled EDTA-containing tubes and centrifuged; plasma was stored at $-20^{\circ} \mathrm{C}$ until assay. ACTH was measured using a two-site immunoradiometric assay obtained in kit form (DiaSorin, Stillwater, MN), with intraassay and interassay coefficients of variation of 3 and $9 \%$, respectively, and a sensitivity of $5 \mathrm{pg} / \mathrm{ml}$. Plasma corticosterone was measured without extraction, using an antiserum raised in rabbit against a corticosterone-0BSA conjugate and ${ }^{125} \mathrm{I}$-corticosteroneBSA as tracer. The sensitivity of the assay was $0.8 \mu \mathrm{g} / \mathrm{dl}$; intraassay and interassay coefficients of variation were 5 and $10 \%$, respectively.

Data analysis. Stereological methods were used to quantify the number of Fos-IR in the PVH. These analyses were performed using a computerassisted morphometry system consisting of a photomicroscope equipped

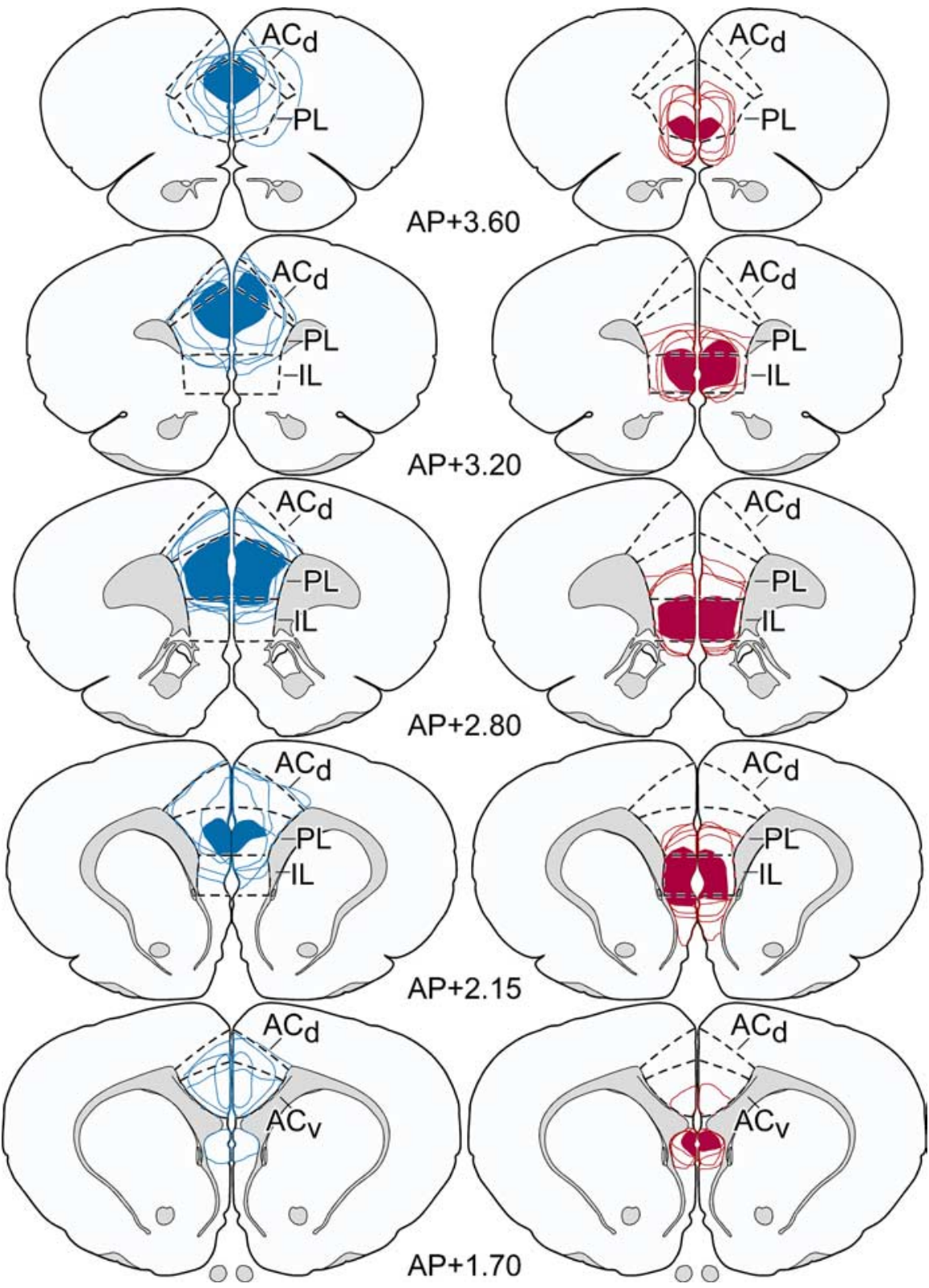

Figure 2. Rostrocaudal extent of mPFC lesion placements. Reconstructions of dorsal (blue) and ventral (red) excitotoxin lesions throughout the bulk of their rostrocaudal extent in mPFC. In each column, solid areas of color represent areas of damage common to all members of each group, and color outlines represent the extent of individual lesions. Dorsal lesions target primarily the PL, with consistent involvement of ventral ACd, whereas ventral lesions are focused in IL, with variable spread into ventral PL. Atlas plates are adapted from Swanson (1992); their distance in millimeters relative to bregma is indicated. AP, Anteroposterior; ACv, anterior cingulate cortex, ventral subdivision.

with an XYZ computer-controlled motorized stage, MicroFire camera (Optronics, Goleta, CA), Gateway microcomputer, and the StereoInvestigator morphometry and stereology software (MicroBrightField, Williston, VT). Anatomical boundaries defining the cell groups of interest were drawn at $25 \times$ using an adjacent series of Nissl-stained sections, and counts of Fos-immunoreactive cells were made on every fifth section through the whole $\mathrm{PVH}$ at $400 \times$ magnification, avoiding cells in the outermost plane of focus. The number of Fos-immunoreactive cells per PVH was then multiplied by 5 to estimate the total number of Fosactivated cells through the entire region. Volume estimates from crosssectional area measurements were obtained using the Cavalieri method to probe for possible treatment effects on PVH volume, but this failed to reach significance (data not shown).

Semiquantitative densitometric analysis of relative levels of CRF mRNA was performed on emulsion-coated slides using Macintosh- 

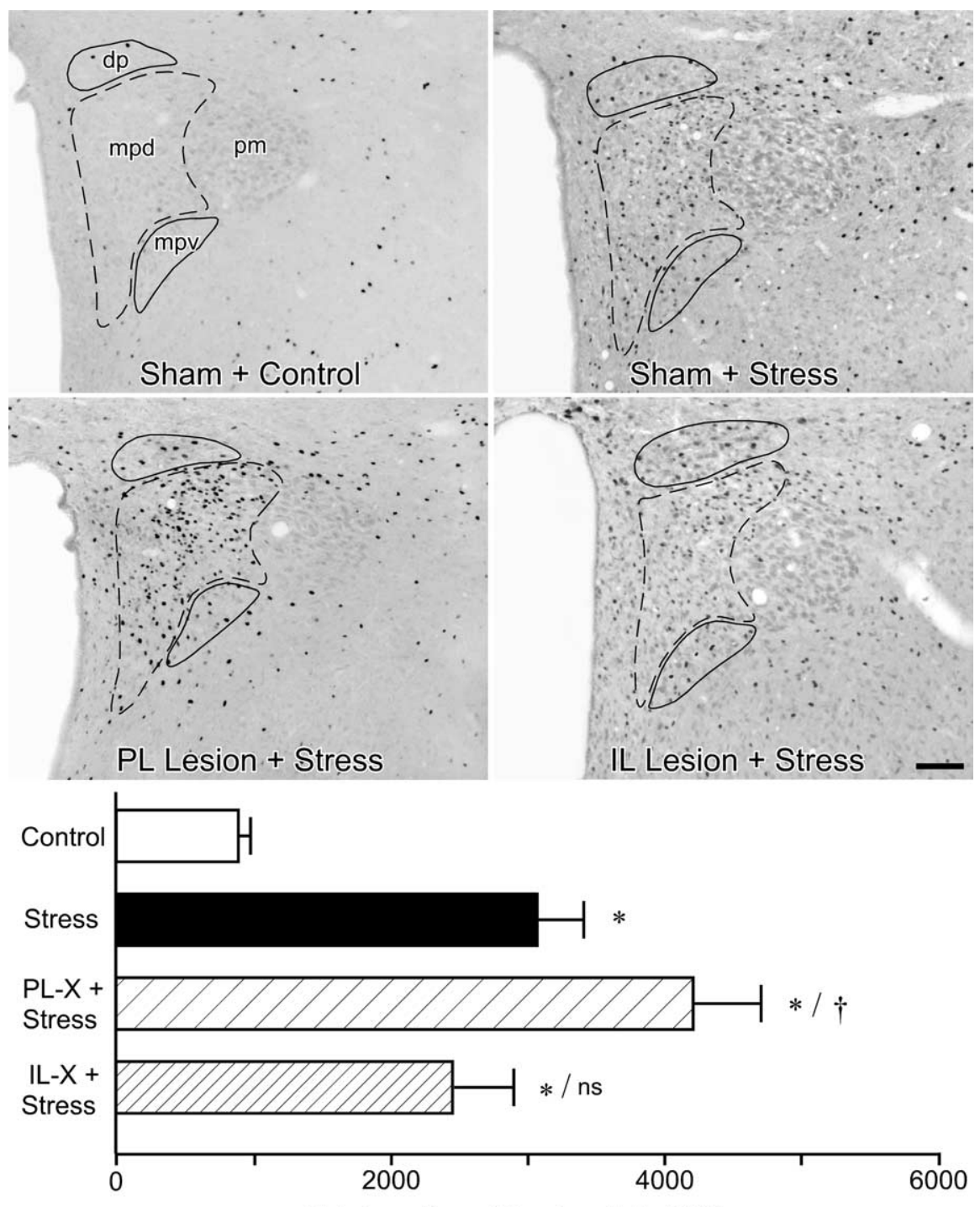

Total number of Fos-ir cells in $\mathrm{PVH}$

Figure 3. Effects of mPFC lesions on PVH activational responses to acute restraint stress. Top, Bright-field photomicrographs showing Fos-IR in PVH as a function of treatment status. Relative to sham-lesioned, unstressed controls, restraint stress ( $30 \mathrm{~min}$ ) results in a marked increase in Fos expression in intact animals focused in the PVHmpd (dashed outline) and secondarily in the autonomic-related dorsal parvicellular (dp) and ventral medial parvicellular (mpv) subdivisions (solid outlines). mPFCd lesions result in a frank enhancement of stress-induced Fos in the CRF-rich hypophysiotropic zone ( $\mathrm{mpd}$ ). In contrast, mPFCv lesions show a mild attenuation of stress-induced Fos-IR in the mpd region but tend to increase responsiveness in preautonomic (dp, mpv) subdivisions. The low level of stress-induced Fos-IR in the posterior magnocellular subdivision (pm) did not show any marked variation with lesion status. Scale bar, $100 \mu \mathrm{m}$ (applies to all). Bottom, Mean \pm SEM number of Fos-immunoreactive neurons in PVH in treatment groups. Stress-induced Fos expression in the PVH is reliably enhanced in mPFCd-lesioned animals. The response of mPFCv-lesioned animals is comparable with that of sham-lesioned animals and still significantly elevated above unstressed control levels. ${ }^{*} p<0.01$, differs significantly from unstressed controls; ${ }^{\dagger} p<0.05$, differs significantly from sham-lesioned stressed animals; $\mathrm{ns}$, Nonsignificant. $n=5$ per group.

driven NIH Image software (version 1.63). The optical densities of hybridization signals were determined under dark-field illumination at $100 \times$ magnification. The hypophysiotropic PVH (i.e., dorsal medial parvicellular subdivision) was defined from Nissl staining pattern (Swanson and Kuypers, 1980) and aligned with corresponding dark-field images of hybridized sections by redirected sampling. Optical density readings, corrected for background, were taken at regularly spaced $(120 \mu \mathrm{m})$ intervals, and average values were determined through the extent of this cell group for each animal. Images from CRF mRNA densitometry were collected using a Hamamatsu (Bridgewater, NJ) Orca CCD camera under the control of OpenLab software (version 3.1.5; Improvision, Lexington, MA). Images collected from each analysis were exported first to Adobe PhotoShop (version 7; Adobe Systems, San Jose, CA) for adjust- ments to optimize/balance contrast and brightness and then to Canvas (version 8; Deneba Systems, Miami, FL) for assembly and labeling.

Statistics. Grouped data from the immunoperoxidase and hybridization histochemical analyses were compared with a one-way ANOVA for lesion (mPFCd, mPFCv, and sham) and treatment (sham-control and shamstress) status, followed by post hoc pairwise comparisons using Bonferroni's correction. Group data from the hormone assays were compared with a mixed-design ANOVA with one within-group (time) and one betweengroup (lesion status) variable, followed by individual pairwise comparisons as above. Data were expressed as the mean \pm SEM.

\section{Results}

\section{Lesion placements}

The placement and extent of $\mathrm{mPFC}$ lesions were evaluated with reference to standard cytoarchitectonic parcellations of the region (Krettek and Price, 1977; Vogt and Peters, 1981). Three fields are of primary interest (from dorsal-to-ventral): the dorsal subdivision of the anterior cingulate area (ACd), PL, and IL. In Nissl material, the ACd is characterized by a sparse layer III and a loosely packed and broad layer V, distinguishing it from PL, which contains a more homogeneous layer $\mathrm{V}$ with large, darkly stained cells. IL exhibits a relatively indistinct lamination pattern and is marked by an irregular border between layers I and II.

Representative ibotenic acid lesions to mPFCd and mPFCv are shown in Figure 1. Stereotaxic coordinates for each site were modified in pilot studies to center excitotoxin injections in PL and IL, respectively, while minimizing overlap between the two placements. Targeting was facilitated by administering smaller volumes of ibotenic acid at high concentrations $(10 \mu \mathrm{g} / \mu \mathrm{l})$, near the limit of solubility for this compound. Dorsal (mPFCd) lesions were centered in PL and typically spread to involve rostral portions of ACd and, to a lesser extent, caudally into the ventral anterior cingulate area, immediately dorsal to the genu of the corpus callosum (Fig. 2, left). Rostral portions of PL were less extensively and consistently targeted by mPFCd lesions than caudal aspects. mPFCv lesions consistently encompassed nearly the entire extent of IL, with variable spread into ventral PL (Fig. 2, right).

\section{Lesion effects on PVH activational responses to acute restraint stress}

We initially surveyed the effects of mPFC lesions on stressinduced expression of Fos protein, a generic marker of neuronal activation, in the PVH of animals killed $2 \mathrm{~h}$ after the termination of a single exposure to restraint stress. The $2 \mathrm{~h}$ time point represents the interval at which maximal Fos induction has been reported in this paradigm (Viau and Sawchenko, 2002). Relative to 

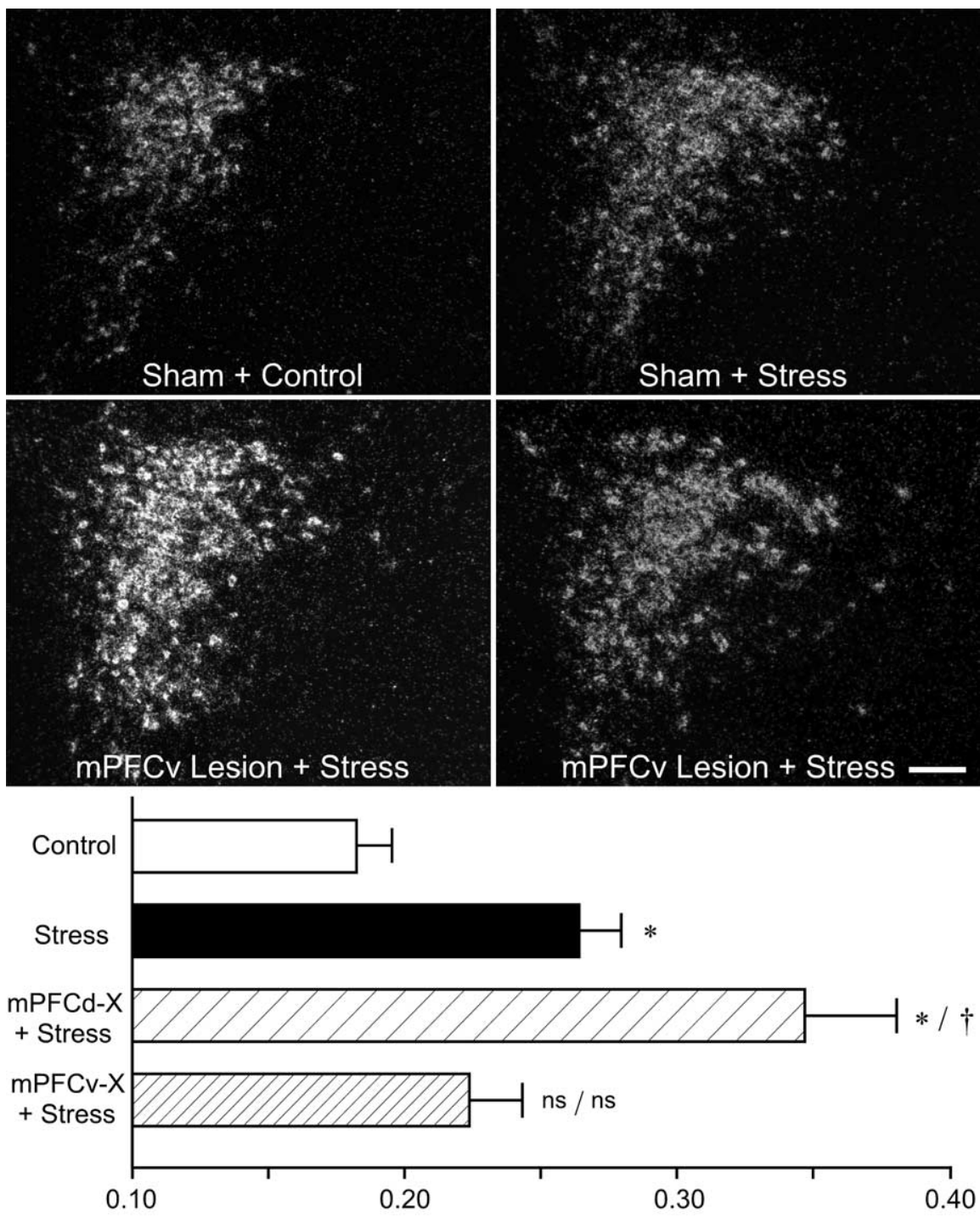

CRF mRNA expression (optical density)

Figure 4. Effects of mPFC lesions on acute restraint-induced CRF mRNA expression in the PVH. Top, Dark-field photomicrographs showing CRF mRNA expression in the PVH as a function of treatment condition. Restraint stress results in a marked increase in CRF mRNA expression in the PVHmpd of intact animals, which was reliably enhanced in mPFCd-lesioned rats. No such enhancement of stress-induced CRF mRNA expression was seen in mPFCv-lesioned animals. Bottom, Relative levels (mean \pm SEM) of CRF mRNA expression in the PVH as a function of treatment condition. Stress exposure reliably increases relative levels of CRF mRNA, and PL lesions significantly enhance this effect. Values from IL-lesioned animals are intermediate between unlesioned stressed and nonstressed controls, not differing reliably from mean values of either of these groups. ${ }^{*} p<0.05$, differs significantly from unstressed controls; ${ }^{\dagger} p<0.01$, differs significantly from sham-lesioned stressed animals; ns, Nonsignificant. $n=5$ per group.

unstressed controls, acute stress resulted in a marked increase in Fos expression in sham-lesioned animals focused in the CRF-rich hypophysiotropic zone [dorsal medial parvicellular part (mpd)] and secondarily in the autonomic-related (dorsal, ventral medial and lateral parvicellular) subdivisions of the PVH (Fig. 3, top). Comparison of total numbers of Fos-activated cells in PVH revealed a overall significant effect $\left(F_{(3,16)}=13.5 ; p<0.0005\right)$. Individual comparisons revealed that values from stressed groups (sham, mPFCd, and mPFCv lesion) were significantly greater than those of unstressed, sham-lesioned controls (Fig. 3, bottom). Moreover, stress-induced Fos expression in the PVH was reliably enhanced (by 37\%) in mPFCd-lesioned animals compared with sham-lesioned animals $(p<0.05)$. No such enhancement was observed in the response of mPFCv-lesioned animals, which was significantly lower than that of mPFCd-lesioned rats $(p<0.005)$ and comparable with that of sham-lesioned controls $(p=0.3)$. Qualitative assessment of the distribution of Fos cells as a function of treatment suggested that mPFCd lesions resulted in an overt enhancement, and mPFCv lesions a mild attenuation, of stress-induced Fos-IR in the PVHmpd region. The response of $\mathrm{mPFCv}$-lesioned animals was further distinguished by a tendency toward increased responsiveness in preautonomic cell groups of the PVH.

Material from this same experiment was prepared for densitometric analysis of relative levels CRF mRNA expression in $\mathrm{PVH}$ as a function of treatment status, to obtain an independent assessment of lesion effects on an endpoint directly related to HPA activity (Fig. 4, top). Comparison of relative optical densities of CRF mRNA in the PVH revealed an overall significant effect for treatment $\left(F_{(3,15)}=9.0 ; p<\right.$ $0.005)$. Consistent with the Fos expression data, restraint stress resulted in a $46 \%$ increase in CRF mRNA expression in the PVHmpd of intact animals compared with unstressed controls $(p<0.05)$ (Fig. 4, bottom). This effect was again reliably enhanced in mPFCd-lesioned animals, by $34 \%$ relative to sham-lesioned, stressed rats $(p<0.05)$. In contrast, the effect of stress on CRF transcripts in mPFCvlesioned animals was equivocal, not differing significantly from levels seen in nonstressed controls or intact (shamoperated) stressed animals (both $p$ values $=0.3$ ).

It may be noted that the foregoing design did not include lesioned, nonstressed control groups, which may be significant in view of reports of mPFC lesion effects on basal corticosterone levels (Sullivan and Gratton, 1999). To address this issue, we prepared additional groups of mPFCd-, mPFCv-, and sham-lesioned rats for analysis of possible lesion effects on histochemical endpoints. The analysis (data not shown) failed to reveal reliable effects of lesion status on the number of Fos-immunoreactive neurons in $\mathrm{PVH}\left(F_{(2,9)}=0.5 ; p=0.6\right)$ or relative levels of $\mathrm{CRF}$ $\operatorname{mRNA}\left(F_{(2,9)}=0.1 ; p=0.9\right)$.

\section{Lesion effects on stress hormone secretion}

HPA secretory responses to $30 \mathrm{~min}$ of restraint stress were examined in separate groups of sham-, mPFCd-, and mPFCv-lesioned animals (Fig. 5). Lesions in this study were similar in placement and extent to those described above. Mixed-design ANOVA of ACTH data, with time of blood sampling treated as a withinsubjects factor, demonstrated main effects of treatment status $\left(F_{(2,13)}=4.6 ; p<0.05\right)$ and time $\left(F_{(4,13)}=26.5 ; p<0.0001\right)$, as well as a significant interaction between these variables $\left(F_{(8,13)}=\right.$ $5.5 ; p<0.0001)$. Basal ACTH titers did not vary as a function of 

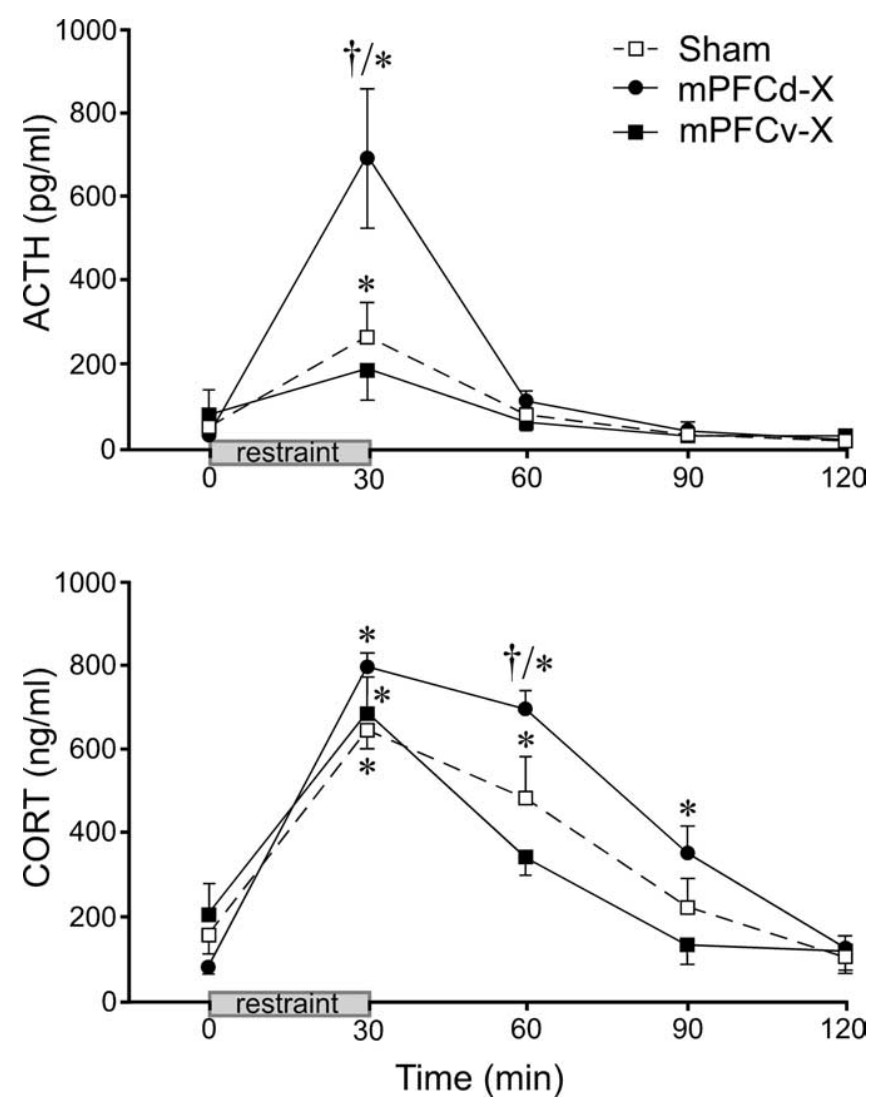

Figure 5. Effects of $\mathrm{mPFC}$ lesions on pituitary-adrenal responses to acute restraint. Mean \pm SEM plasma ACTH (top) and corticosterone (CORT; bottom) levels in sham-, mPFCd-, and mPFCv-lesioned animals measured before and after a single $30 \mathrm{~min}$ restraint session. Top, Stress exposure significantly increases plasma levels of ACTH in sham-lesioned animals (at $30 \mathrm{~min}$ ), and $\mathrm{mPFC}$ lesions produce a marked (2.6-fold) enhancement of this effect. In contrast, plasma ACTH in mPFCv-lesioned animals is not significantly elevated over pre-stress levels $(p=0.2)$. Bottom, Stress exposure also significantly increases plasma CORT levels in sham-lesioned animals (at 30 and $60 \mathrm{~min}$ ). mPFCd lesions result in a prolonged increase in stress-induced plasma CORT ( $p<0.05$ at 30,60, and 90 min compared with $0 \mathrm{~min}$ ), whereas mPFCv-lesioned animals show a more rapid recovery to pre-stress levels ( $p<0.05$ at 30 min only). ${ }^{*} p<0.05$, differs significantly from basal $(0 \mathrm{~min})$ values from within each group; ${ }^{\dagger} p<0.01$, differs significantly from sham-lesioned animals. $n=5$ per group.

lesion status. Within-group comparisons revealed that plasma ACTH levels in the sham lesion group displayed a mild, yet reliable, increase that peaked $(267 \pm 84 \mathrm{pg} / \mathrm{ml})$ immediately after the termination of restraint ( $30 \mathrm{~min}, p<0.01$ ) and was restored to pre-stress levels by $60 \mathrm{~min}(p=0.3)$. ACTH responses in mPFCd-lesioned animals displayed a similar time course but with a markedly elevated peak value $(697 \pm 164 \mathrm{pg} / \mathrm{ml})$ that was significantly greater than the response of sham-lesioned controls $(p<0.01)$. The minor stress-induced rise in ACTH in the $\mathrm{mPFCv}$-lesioned group did not reach significance (0 vs $30 \mathrm{~min}$, $p=0.2$ ).

Plasma corticosterone levels showed similar main effects of lesion status $\left(F_{(2,13)}=4.3 ; p<0.05\right)$, time $\left(F_{(4,13)}=72.7 ; p<\right.$ $0.0001)$, and their interaction $\left(F_{(8,13)}=2.5 ; p<0.02\right)$. From similar basal levels, all groups displayed reliable stress-induced increases in this parameter that achieved comparable mean peak values $(641-792 \mathrm{ng} / \mathrm{ml})$ at the $30 \mathrm{~min}$ time point. Lesion status differentially affected the longevity of the response, with mPFCdlesioned animals displaying reliable elevations relative to baseline values through $90 \mathrm{~min}$ compared with $60 \mathrm{~min}$ for sham-operated controls and $30 \mathrm{~min}$ for the $\mathrm{mPFCv}$-lesioned group. Corticoste- rone titers of the mPFCd group were significantly greater than those of sham-operated animals at the 60 min time point $(p<$ 0.01 )

\section{mPFCv lesions enhance stress-induced recruitment of PVH autonomic neurons}

The foregoing analyses suggest that mPFCv involvement in stress-induced HPA output is subtle and opposite in sign to the pronounced inhibitory influences localized to mPFCd. Previously noted differences in the topography of restraint-induced Fos-IR in the PVH as a function of lesion status raises the possibility of more substantial $\mathrm{mPFCv}$ involvement in modulating autonomic-related PVH outputs. To address this possibility directly, tissue from animals bearing both retrograde tracer (fast blue) implants into the rostral ventrolateral medulla and appropriately placed $\mathrm{mPFCd}, \mathrm{mPFCv}$, or sham lesions and subjected to 30 min restraint (Fig. 6, top) was prepared for dual immunostaining for Fos and tracer immunoreactivities. In each group, dual labeling indicative of stress-sensitive preautonomic neurons was localized overwhelmingly to the dorsal, ventral medial, and lateral parvicellular subdivisions of PVH. Counts of double-labeled cells (Fig. 6, bottom) revealed a significant overall effect of lesion status $\left(F_{(2,8)}=25.2 ; p<0.0005\right)$, with values from mPFCvlesioned rats being $90 \%$ greater than those of sham-operated controls $(p<0.001)$, whereas mPFCd lesions did not result in any reliable difference in this comparison $(p=0.69)$. A variation of this experiment was performed in which fast blue injections were placed in upper thoracic spinal cord (T1-T2) to more specifically label PVH outputs relevant to sympathetic control, in sham- and $\mathrm{mPFCv}$-lesioned animals. As expected, restraint stress resulted in a $63 \%$ increase in the proportion of retrogradely labeled Fospositive neurons in PVH after mPFCv lesions $(t=2.6$; $p<0.05$; data not shown).

\section{Discussion}

These results support a regional differentiation of the $\mathrm{mPFC}$ with respect to its capacity to modulate stress-related PVH outputs. Acute restraint-induced activation of independent measures of HPA cellular and secretory activity were markedly exaggerated after lesions of mPFCd and mildly suppressed in mPFCvlesioned animals. In contrast, $\mathrm{mPFCv}$ ablation selectively enhanced the stress-induced recruitment of identified PVH preautonomic neurons. Neither lesion affected basal levels of any measure used here. Thus, the present findings localize the previously documented HPA-inhibitory influence of mPFC to its dorsal region and indicate that ventral $\mathrm{mPFC}$ activates HPA output while concurrently inhibiting central autonomic outflow through the PVH.

Although stimulation of the prefrontal cortex was reported to modulate adrenal corticosteroid output in older literature (Porter, 1954; Hall and Marr, 1975), it was the work of Diorio et al. (1993) that focused attention on its involvement in stressinduced HPA responses. This seminal study showed that mPFC lesions result in augmented HPA secretory responses under emotional stress, whereas intra-mPFC administration of corticosterone attenuated stress-induced HPA activation. Subsequent work has generally supported an inhibitory involvement of mPFC in HPA control (Brake et al., 2000; Figueiredo et al., 2003; Spencer et al., 2005), although with several notable exceptions. A few reports have described decreased basal, but not stressinduced, HPA secretory responses in rats bearing extensive mPFC lesions (Jinks and McGregor, 1997; Sullivan and Gratton, 1999, 2002), whereas another showed that electrolytic lesions in- 

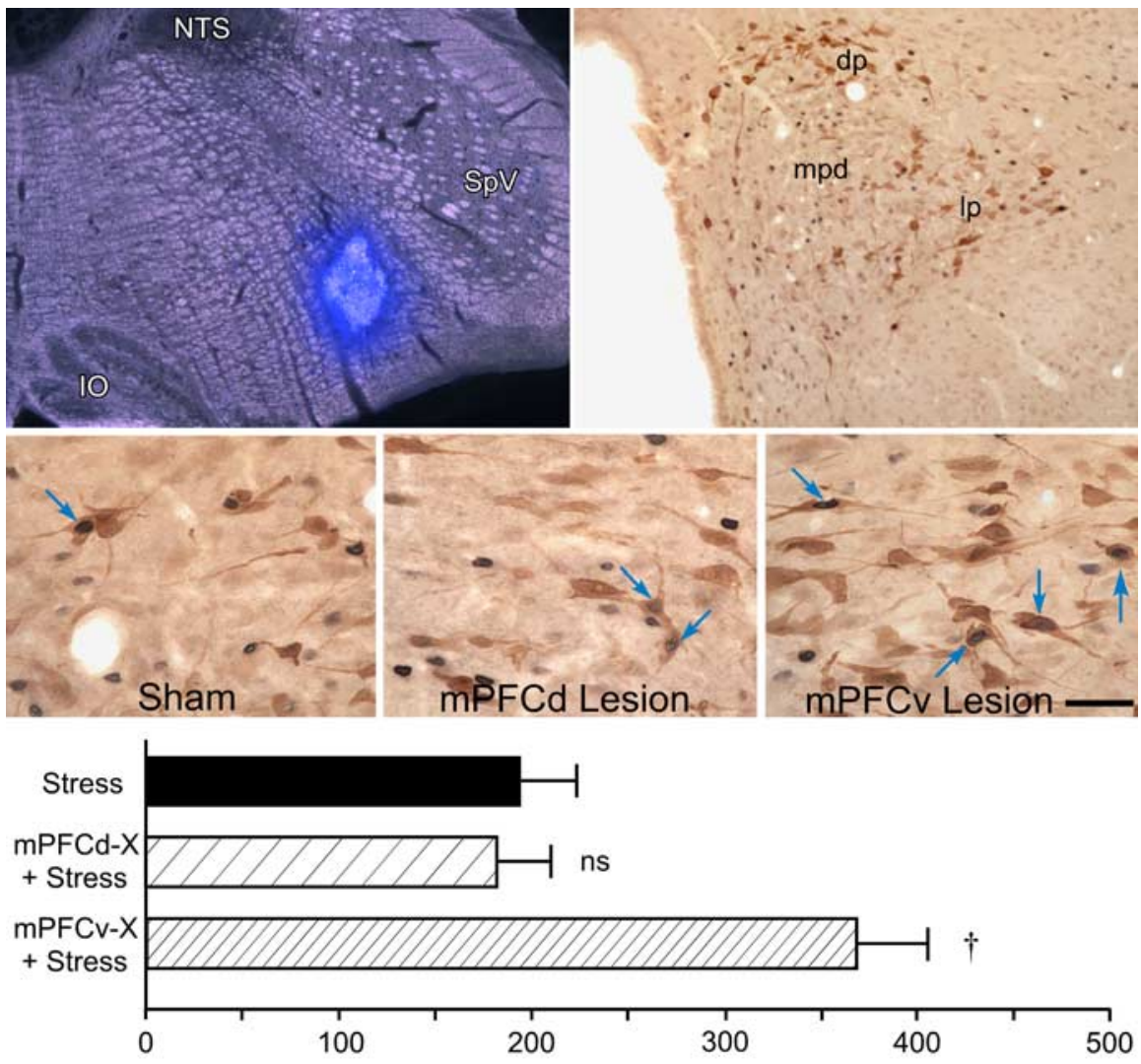

No. activated (Fos) preautonomic (Fast Blue) neurons in PVH

Figure 6. Acute restraint stress increases activation of preautonomic PVH after mPFCv lesions. Top left, Dark-field/fluorescence photomicrograph showing a fast blue tracer deposit in ventrolateral medulla. Tracer deposits were aimed at the descending PVH pathway to both the dorsal vagal complex and spinal cord, to maximally label preautonomic neurons in the PVH. I0, Inferior olive; $\mathrm{SpV}$, spinal trigeminal nucleus. Top right, Bright-field photomicrograph showing stress-induced Fos-IR (black nuclei) and fast blue labeling (brown cytoplasm) in PVH. Retrogradely labeled cells are concentrated in aspects of the PVH (dp, Ip) distinct from the principal seat of hypophysiotropic neurons in the PVHmpd. dp, Dorsal posterior subdivision; Ip, lateral subdivision. Middle, Bright-field photomicrographs showing examples (arrows) of double-labeling for Fos and fast blue in the dorsal parvicellular PVH in the three stressed groups; note the greater number of doubly labeled neurons in the stressed, mPFCv-lesioned example, relative to the sham-operated and mPFCd-lesioned conditions. Scale bar (applies to all three): top right, $0.5 \mathrm{~mm}$; top left, $100 \mu \mathrm{m}$; middle, $25 \mu \mathrm{m}$ (applies to all three). Bottom, Mean \pm SEM number of double-labeled neurons as a function of treatment condition. $\mathrm{mPFC}$, but not $\mathrm{mPFCd}$, lesions result in a significant increase in the number of stress-responsive preautonomic neurons in the PVH. ${ }^{\dagger} p<0.01$, differs significantly from sham-lesioned stressed animals. $n=4$ per group.

volving PL and IL augmented the response to physiological but not emotional stressors (Crane et al., 2003). Despite providing limited details of lesion placement and extent, these studies offered some basis for inferring a dorsoventral distinction in mPFC control, as was observed in the present study.

Our findings localize the HPA-inhibitory influences during acute emotional stress to the mPFCd, specifically including the caudal two-thirds of PL and ventral ACd, at least. Although discrepancies in the literature noted above might have suggested a tonic inhibitory role for mPFCv (principally IL), our data fail to support this, instead providing evidence for a mild facilitatory influence during stress, because ventral lesions blunted restraintinduced enhancements in CRF mRNA and plasma hormone levels. The basis for these disparities is unclear and may include differences in lesion placement/extent, stressor duration, and methods used to characterize HPA responsiveness. Based on reconstructions of lesions that differentially targeted mPFC subfields and convergent findings from independent HPA-related endpoints, we are confident in our conclusion that mPFC components are differentiated with respect to both the nature of their influence on HPA control mechanisms (excitatory versus inhibitory) and, by inference, the circuitry through which such influences are effected (Fig. 7).

The MPFCv may be distinguished not only in the nature of its involvement in HPA control but also in its unique position to modulate autonomic outflow during stress. The mPFC has long been implicated in the higher-order regulation of autonomic function (Spencer, 1894; Howell and Austin, 1900; Jackson, 1931), and more recent evidence supports a privileged role for IL in this regard (for review, see Neafsey, 1990). The IL projects to brainstem cell groups involved in central autonomic control, including the nucleus of the solitary tract (NTS), the principal central terminus of interoceptive inputs carried by the vagus and glossopharyngeal nerves (Saper, 1982; Terreberry and Neafsey, 1987). The present findings suggest that the preautonomic compartment of the PVH is also subject to mPFCv influences, albeit probably not directly (see below). Long descending projections of the $\mathrm{PVH}$ innervate directly the principal sensory (NTS) and motor nuclei of the vagus and sympathetic preganglionic cell groups in thoracolumbar spinal cord (Swanson and Kuypers, 1980). This population has been repeatedly implicated in transneuronal tracing studies as a major source of the central presympathetic innervation of a host of peripheral tissues (Strack et al., 1989), as well as a prominent seat of neurons in a position to influence concurrently both cardiac and adrenal medullary activity, which have been considered as "command" neurons for the fight-orflight response (Jansen et al., 1995). Accordingly, functional studies have linked this projection to a range of cardiovascular, renal, and metabolic processes that may be considered as adaptive responses to acute stress (Elmquist, 2001; Benarroch et al., 2005; Coote, 2005).

The mPFC is classically defined on the basis of cytoarchitectonics and its inputs from the midline and intralaminar thalamic nuclei (for review, van Eden et al., 1990). Nonetheless, it engages in patterns of connectivity that may cut across cytoarchitectonic boundaries in a manner consistent with the functional heterogeneity suggested here. Although the dorsal mPFC (i.e., anterior cingulate and dorsal PL) has connections predominantly with sensorimotor and association neocortical regions, the ventral mPFC (ventral PL and IL) shares more extensive connections with temporal/limbic association cortices, the amygdala, and hypothalamus (Sesack et al., 1989; Floyd et al., 2001; Heidbreder and Groenewegen, 2003; Vertes, 2004). Diencephalic mPFC projections distribute diffusely throughout areas closely adjoining the PVH but very sparsely within the nucleus, proper (Sesack et al., 1989; Hurley et al., 1991; Vertes, 2004). These peri-PVH regions are enriched in GABAergic interneurons implicated in the tonic and phasic inhibitory control of HPA and other PVH re- 


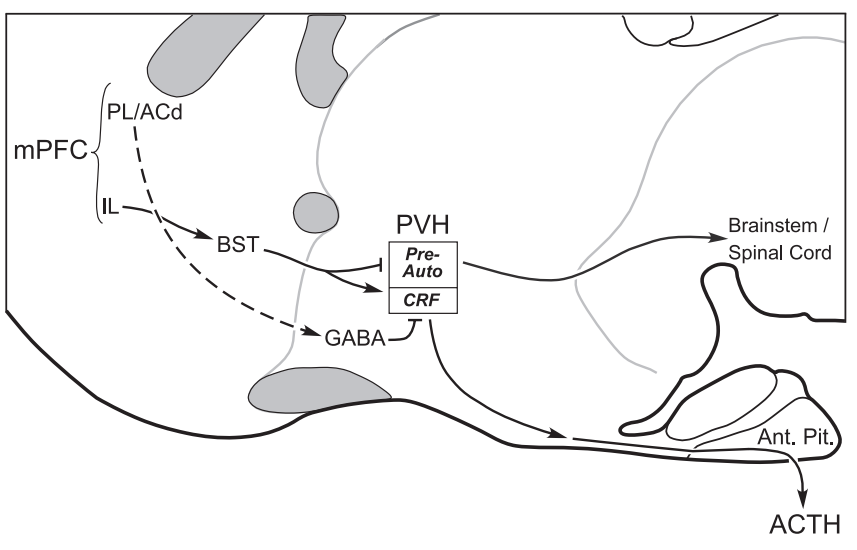

Figure 7. Separate pathways from $\mathrm{mPFC}$ may differentially regulate PVH responses to stress. Schematic drawing of a sagittal section through basal forebrain highlighting possible circuitry by which the $\mathrm{mPFC}$ may influence stress-related PVH effector mechanisms. The present results suggest that distinct pathways from the mPFCd and mPFCv may be involved in the differential regulation of neuroendocrine and autonomic outputs by acute emotional stress. The dashed line from ACd/PL to GABAergic cell groups indicates that the projection has not been formally established. ac, Anterior commissure; Ant. Pit., anterior pituitary; BST, bed nucleus of the stria terminalis; cc, corpus callosum; ot, optic tract; Pre-Auto, preautonomic subdivisions.

sponse systems (Roland and Sawchenko, 1993; Boudaba et al., 1996). Although direct evidence to define such circuitry (Fig. 7) is lacking, the idea that local GABAergic neurons provide a relay through which $\mathrm{mPFC}$ influences are exerted on the stress axes (Roland and Sawchenko, 1993; Herman et al., 2003, 2005) is consistent with evidence that extrinsic mPFC projections are overwhelmingly excitatory (glutamatergic) (Ottersen et al., 1995), although its influence on HPA activation is predominantly inhibitory (Diorio et al., 1993; Brake et al., 2000; Figueiredo et al., 2003; Spencer et al., 2005). It should also be noted that evidence has been provided for a facilitatory influence of IL on HPA output mediated via the bed nucleus of the stria terminalis (Crane et al., 2003; Choi et al., 2004), which may be germane to the attenuated HPA response profile we observe after mPFCv lesions.

Emotional stressors are commonly viewed as comprising stimuli that target one or more exteroceptive sensory modalities and involve distinct cognitive (i.e., comparison with past experience) and affective components. Stressors of this type activate a seemingly stereotyped set of highly interconnected cell groups in the limbic forebrain, including aspects of the septum, amygdala, bed nucleus, hippocampus, and mPFC (Cullinan et al., 1995; Campeau et al., 1997; Li and Sawchenko, 1998; Dayas et al., 2001). Each of these regions has been implicated in the positive or negative regulation of the HPA axis via neuronal mechanisms and/or as targets of glucocorticoid negative feedback (Sapolsky et al., 1984; Kovacs and Makara, 1988; Herman et al., 2003, 2005). Relative to current formulations of the role of mPFC in central stress circuitry, the present findings are consistent with the idea that the dominant connections of dorsal and ventral mPFC are with other regions associated with stress inhibition and facilitation, respectively (Herman et al., 2003, 2005), at least insofar as the HPA axis is concerned. However, the fact that the nature of $\mathrm{mPFCd} / \mathrm{mPFCv}$ involvement in autonomic control does not adhere to this scheme may indicate that the mPFC modulation of the neuroendocrine and autonomic arms of the stress response occurs in a patterned and regionally differentiated manner. Indeed, behavioral studies that have endeavored to parse the roles of dorsal versus ventral mPFC generally support an involvement of both regions in given cognitive or affective functions but in distinct aspects of them (Morgan and LeDoux, 1995; Heidbreder and Groenewegen, 2003).

The present findings may hold relevance to understanding adaptations to chronic stress. For example, the posterior paraventricular nucleus of the thalamus (PVTp) has been implicated as a critical node in circuitry subserving decrements in HPA output (habituation) commonly seen on repeated exposure to the same stressor, as well as the exaggerated responses to introduction of a novel challenge (facilitation) (Bhatnagar and Dallman, 1998; Bhatnagar et al., 2002). The PVTp projection to $\mathrm{mPFC}$ targets IL in a highly preferential manner (Moga et al., 1995), warranting consideration of this region in the adaptive adjustments of the axis to chronic stress. From a pathological perspective, neuroimaging studies reveal functional impairment and shrinkage of mPFC in posttraumatic stress disorder (PTSD) (Rauch et al., 2003; Shin et al., 2005) that find a parallel in reports of dendritic atrophy and synapse loss after chronic emotional stress in rodents (Cook and Wellman, 2004; Radley et al., 2004, 2006). PTSD is associated with HPA axis dysregulation that may be variable in nature (for review, see Newport and Nemeroff, 2000; Yehuda, 2001) and consistent increases in cardiovascular reactivity (Peri et al., 2000; Shalev et al., 2000). In these contexts, and even in Fos-based studies of activational profiles elicited by various stress paradigms, the $\mathrm{mPFC}$ has tended to be treated as a unitary structure. The present findings, along with recent indications of IL-PL differences in sensitivity to emotional stressors (Izquierdo et al., 2006), suggest that finer grained analyses of mPFC should foster clarification of functional circuits underlying stress adaptation and their involvement in affective disorders.

\section{References}

Antoni FA (1986) Hypothalamic control of adrenocorticotropin secretion: advances since the discovery of 41-residue corticotropin-releasing factor. Endocr Rev 7:351-378.

Benarroch EE, Schmeichel AM, Low PA, Boeve BF, Sandroni P, Parisi JE (2005) Involvement of medullary regions controlling sympathetic output in Lewy body disease. Brain 128:338-344.

Bhatnagar S, Dallman M (1998) Neuroanatomical basis for facilitation of hypothalamic-pituitary-adrenal responses to a novel stressor after chronic stress. Neuroscience 84:1025-1039.

Bhatnagar S, Huber R, Nowak N, Trotter P (2002) Lesions of the posterior paraventricular thalamus block habituation of hypothalamic-pituitaryadrenal responses to repeated restraint. J Neuroendocrinol 14:403-410.

Boudaba C, Szabo K, Tasker JG (1996) Physiological mapping of local inhibitory inputs to the hypothalamic paraventricular nucleus. J Neurosci 16:7151-7160.

Brake WG, Flores G, Francis D, Meaney MJ, Srivastava LK, Gratton A (2000) Enhanced nucleus accumbens dopamine and plasma corticosterone stress responses in adult rats with neonatal excitotoxic lesions to the medial prefrontal cortex. Neuroscience 96:687-695.

Bush G, Whalen PJ, Rosen BR, Jenike MA, McInerney SC, Rauch SL (1998) The counting Stroop: an interference task specialized for functional neuroimaging — validation study with functional MRI. Hum Brain Mapp $6: 270-282$.

Bush G, Luu P, Posner MI (2000) Cognitive and emotional influences in anterior cingulate cortex. Trends Cogn Sci 4:215-222.

Campeau S, Falls WA, Cullinan WE, Helmreich DL, Davis M, Watson SJ (1997) Elicitation and reduction of fear: behavioural and neuroendocrine indices and brain induction of the immediate-early gene c-fos. Neuroscience 78:1087-1104.

Chang HT, Kuo H, Whittaker JA, Cooper NG (1990) Light and electron microscopic analysis of projection neurons retrogradely labeled with Fluoro-Gold: notes on the application of antibodies to Fluoro-Gold. J Neurosci Methods 35:31-37.

Choi DC, Dolgas CM, Herman JP (2004) The role of the bed nucleus of the stria terminalis in regulating the HPA axis. Soc Neurosci Abstr 30:425.23.

Cook SC, Wellman CL (2004) Chronic stress alters dendritic morphology in rat medial prefrontal cortex. J Neurobiol 60:236-248. 
Coote JH (2005) A role for the paraventricular nucleus of the hypothalamus in the autonomic control of heart and kidney. Exp Physiol 90:169-173.

Crane JW, Ebner K, Day TA (2003) Medial prefrontal cortex suppression of the hypothalamic-pituitary-adrenal axis response to a physical stressor, systemic delivery of interleukin-1beta. Eur J Neurosci 17:1473-1481.

Cullinan WE, Herman JP, Battaglia DF, Akil H, Watson SJ (1995) Pattern and time course of immediate early gene expression in rat brain following acute stress. Neuroscience 64:477-505.

Dayas CV, Buller KM, Crane JW, Xu Y, Day TA (2001) Stressor categorization: acute physical and psychological stressors elicit distinctive recruitment patterns in the amygdala and in medullary noradrenergic cell groups. Eur J Neurosci 14:1143-1152.

Diorio D, Viau V, Meaney MJ (1993) The role of the medial prefrontal cortex (cingulate gyrus) in the regulation of hypothalamic-pituitary-adrenal responses to stress. J Neurosci 13:3839-3847.

Elmquist JK (2001) Hypothalamic pathways underlying the endocrine, autonomic, and behavioral effects of leptin. Int J Obes Relat Metab Disord 25 [Suppl 5]:S78-S82.

Ericsson A, Kovacs KJ, Sawchenko PE (1994) A functional anatomical analysis of central pathways subserving the effects of interleukin-1 on stressrelated neuroendocrine neurons. J Neurosci 14:897-913.

Figueiredo HF, Bruestle A, Bodie B, Dolgas CM, Herman JP (2003) The medial prefrontal cortex differentially regulates stress-induced c-fos expression in the forebrain depending on type of stressor. Eur J Neurosci 18:2357-2364.

Floyd NS, Price JL, Ferry AT, Keay KA, Bandler R (2001) Orbitomedial prefrontal cortical projections to hypothalamus in the rat. J Comp Neurol 432:307-328

Gabbott PL, Warner TA, Jays PR, Salway P, Busby SJ (2005) Prefrontal cortex in the rat: projections to subcortical autonomic, motor, and limbic centers. J Comp Neurol 492:145-177.

Hall RE, Marr HB (1975) Influence of electrical stimulation of posterior orbital cortex upon plasma cortisol levels in unanesthetized sub-human primate. Brain Res 93:167-171.

Heidbreder CA, Groenewegen HJ (2003) The medial prefrontal cortex in the rat: evidence for a dorso-ventral distinction based upon functional and anatomical characteristics. Neurosci Biobehav Rev 27:555-579.

Herman JP, Figueiredo H, Mueller NK, Ulrich-Lai Y, Ostrander MM, Choi DC, Cullinan WE (2003) Central mechanisms of stress integration: hierarchical circuitry controlling hypothalamo-pituitary-adrenocortical responsiveness. Front Neuroendocrinol 24:151-180.

Herman JP, Ostrander MM, Mueller NK, Figueiredo H (2005) Limbic system mechanisms of stress regulation: hypothalamo-pituitary-adrenocortical axis. Prog Neuropsychopharmacol Biol Psychiatry 29:1201-1213.

Howell WH, Austin MF (1900) The effect of stimulating various portions of the cortex cerebri, caudate nucleus and dura mater on blood pressure. Am J Physiol 3:xxii-xxiii.

Hurley KM, Herbert H, Moga MM, Saper CB (1991) Efferent projections of the infralimbic cortex of the rat. J Comp Neurol 308:249-276.

Izquierdo A, Wellman CL, Holmes A (2006) Brief uncontrollable stress causes dendritic retraction in infralimbic cortex and resistance to fear extinction in mice. J Neurosci 26:5733-5738.

Jackson JH (1931) Clinical and physiological researches on the nervous system. I. On the anatomical and physiological localization of movements in the brain. London: Hodder and Stoughton.

Jansen AS, Nguyen XV, Karpitskiy V, Mettenleiter TC, Loewy AD (1995) Central command neurons of the sympathetic nervous system: basis of the fight-or-flight response. Science 270:644-646.

Jinks AL, McGregor IS (1997) Modulation of anxiety-related behaviours following lesions of the prelimbic or infralimbic cortex in the rat. Brain Res 772:181-190.

Kerns JG, Cohen JD, MacDonald AW, 3rd, Cho RY, Stenger VA, Carter CS (2004) Anterior cingulate conflict monitoring and adjustments in control. Science 303:1023-1026.

Kovacs KJ, Makara GB (1988) Corticosterone and dexamethasone act at different brain sites to inhibit adrenalectomy-induced adrenocorticotropin hypersecretion. Brain Res 474:205-210.

Krettek JE, Price JL (1977) Projections from the amygdaloid complex to the cerebral cortex and thalamus in the rat and cat. J Comp Neurol 172:687-722.

Li HY, Sawchenko PE (1998) Hypothalamic effector neurons and extended circuitries activated in "neurogenic" stress: a comparison of footshock effects exerted acutely, chronically, and in animals with controlled glucocorticoid levels. J Comp Neurol 393:244-266.

MacDonald III AW, Cohen JD, Stenger VA, Carter CS (2000) Dissociating the role of the dorsolateral prefrontal and anterior cingulate cortex in cognitive control. Science 288:1835-1838.

Moga MM, Weis RP, Moore RY (1995) Efferent projections of the paraventricular thalamic nucleus in the rat. J Comp Neurol 359:221-238.

Morgan MA, LeDoux JE (1995) Differential contribution of dorsal and ventral medial prefrontal cortex to the acquisition and extinction of conditioned fear in rats. Behav Neurosci 109:681-688.

Neafsey EJ (1990) Prefrontal cortical control of the autonomic nervous system: anatomical and physiological observations. Prog Brain Res 85:147165; discussion 165-166.

Newport DJ, Nemeroff CB (2000) Neurobiology of posttraumatic stress disorder. Curr Opin Neurobiol 10:211-218.

Ottersen OP, Hjelle OP, Osen KK, Laake JH (1995) Amino acid transmitters, Ed 2. San Diego: Academic.

Peri T, Ben-Shakhar G, Orr SP, Shalev AY (2000) Psychophysiologic assessment of aversive conditioning in posttraumatic stress disorder. Biol Psychiatry 47:512-519.

Porter RW (1954) The central nervous system and stress-induced eosinopenia. Recent Progr Horm Res 10:1-27.

Radley JJ, Sawchenko PE (2005) Differential role of the dorsal versus ventral medial prefrontal cortex (mPFC) in paraventricular hypothalamic responses to acute restraint stress. Soc Neurosci Abstr 31:637.11.

Radley JJ, Rocher AB, Hao J, McCall T, Wang A, Hof PR, McEwen BS, Morrison JH (2004) Chronic behavioral stress decreases apical dendritic spine density in the medial prefrontal cortex. Soc Neurosci Abstr 30:208.201.

Radley JJ, Rocher AB, Miller M, Janssen WG, Liston C, Hof PR, McEwen BS, Morrison JH (2006) Repeated stress induces dendritic spine loss in the rat medial prefrontal cortex. Cereb Cortex 16:313-320.

Rauch SL, Shin LM, Segal E, Pitman RK, Carson MA, McMullin K, Whalen PJ, Makris N (2003) Selectively reduced regional cortical volumes in post-traumatic stress disorder. NeuroReport 14:913-916.

Roland BL, Sawchenko PE (1993) Local origins of some GABAergic projections to the paraventricular and supraoptic nuclei of the hypothalamus in the rat. J Comp Neurol 332:123-143.

Saper CB (1982) Convergence of autonomic and limbic connections in the insular cortex of the rat. J Comp Neurol 210:163-173.

Saper CB, Loewy AD, Swanson LW, Cowan WM (1976) Direct hypothalamo-autonomic connections. Brain Res 117:305-312.

Sapolsky RM, Krey LC, McEwen BS (1984) Glucocorticoid-sensitive hippocampal neurons are involved in terminating the adrenocortical stress response. Proc Natl Acad Sci USA 81:6174-6177.

Sawchenko PE, Swanson LW (1982) Immunohistochemical identification of neurons in the paraventricular nucleus of the hypothalamus that project to the medulla or to the spinal cord in the rat. J Comp Neurol 205:260-272.

Sawchenko PE, Cunningham Jr ET, Mortrud MT, Pfeiffer SW, Gerfen CR (1990) Phaseolus vulgaris-leucoagglutanin (PHA-L) anterograde axonal transport technique. Methods Neurosci 3:247-260.

Schiltz JC, Sawchenko PE (2002) Distinct brain vascular cell types manifest inducible cyclooxygenase expression as a function of the strength and nature of immune insults. J Neurosci 22:5606-5618.

Sesack SR, Deutch AY, Roth RH, Bunney BS (1989) Topographical organization of the efferent projections of the medial prefrontal cortex in the rat: an anterograde tract-tracing study with Phaseolus vulgaris leucoagglutinin. J Comp Neurol 290:213-242.

Shalev AY, Peri T, Brandes D, Freedman S, Orr SP, Pitman RK (2000) Auditory startle response in trauma survivors with posttraumatic stress disorder: a prospective study. Am J Psychiatry 157:255-261.

Shin LM, Wright CI, Cannistraro PA, Wedig MM, McMullin K, Martis B, Macklin ML, Lasko NB, Cavanagh SR, Krangel TS, Orr SP, Pitman RK, Whalen PJ, Rauch SL (2005) A functional magnetic resonance imaging study of amygdala and medial prefrontal cortex responses to overtly presented fearful faces in posttraumatic stress disorder. Arch Gen Psychiatry 62:273-281

Shu SY, Ju G, Fan LZ (1988) The glucose oxidase-DAB-nickel method in peroxidase histochemistry of the nervous system. Neurosci Lett 85:169-171.

Simmons DM, Arriza JL, Swanson LW (1989) A complete protocol for in 
situ hybridization of messenger RNAs in brain and other tissues with radiolabeled single-stranded RNA probes. J Histotechnol 12:169-181.

Spencer SJ, Buller KM, Day TA (2005) Medial prefrontal cortex control of the paraventricular hypothalamic nucleus response to psychological stress: possible role of the bed nucleus of the stria terminalis. J Comp Neurol 481:363-376.

Spencer WG (1894) The effect produced on respiration by faradic excitation of the cerebrum in the monkey, dog, cat, and rabbit. Philos Trans R Soc Lond B Biol Sci 185b:609-657.

Strack AM, Sawyer WB, Hughes JH, Platt KB, Loewy AD (1989) A general pattern of CNS innervation of the sympathetic outflow demonstrated by transneuronal pseudorabies viral infections. Brain Res 491:156-162.

Sullivan RM (2004) Hemispheric asymmetry in stress processing in rat prefrontal cortex and the role of mesocortical dopamine. Stress 7:131-143.

Sullivan RM, Gratton A (1999) Lateralized effects of medial prefrontal cortex lesions on neuroendocrine and autonomic stress responses in rats. J Neurosci 19:2834-2840.

Sullivan RM, Gratton A (2002) Behavioral effects of excitotoxic lesions of ventral medial prefrontal cortex in the rat are hemisphere-dependent. Brain Res 927:69-79.

Swanson LW (1992) Brain maps: structure of the rat brain. Amsterdam: Elsevier.
Swanson LW, Kuypers HG (1980) The paraventricular nucleus of the hypothalamus: cytoarchitectonic subdivisions and organization of projections to the pituitary, dorsal vagal complex, and spinal cord as demonstrated by retrograde fluorescence double-labeling methods. J Comp Neurol 194:555-570.

Terreberry RR, Neafsey EJ (1987) The rat medial frontal cortex projects directly to autonomic regions of the brainstem. Brain Res Bull 19:639-649.

van Eden CG, Kros JM, Uylings HB (1990) The development of the rat prefrontal cortex. Its size and development of connections with thalamus, spinal cord and other cortical areas. Prog Brain Res 85:169-183.

Vertes RP (2004) Differential projections of the infralimbic and prelimbic cortex in the rat. Synapse 51:32-58.

Viau V, Sawchenko PE (2002) Hypophysiotropic neurons of the paraventricular nucleus respond in spatially, temporally, and phenotypically differentiated manners to acute vs. repeated restraint stress: rapid publication. J Comp Neurol 445:293-307.

Vogt BA, Peters A (1981) Form and distribution of neurons in rat cingulate cortex: areas 32, 24, and 29. J Comp Neurol 195:603-625.

Yehuda R (2001) Biology of posttraumatic stress disorder. J Clin Psychiatry 62 [Suppl 17]:41-46. 